\title{
NOTES
}

\section{Solid-Liquid-Solid Triphase Transfer Reaction of Poly(chloromethylstyrene)}

\author{
Takashi IIZAWA, ${ }^{*}$ Shoji AKATSUKA, and Tadatomi NisHIKUBO \\ Department of Applied Chemistry, Faculty of Engineering, \\ Kanagawa University, Rokkakubashi, Kanagawa-ku, \\ Yokohama 221, Japan \\ (Received July 6, 1987)
}

\begin{abstract}
KEY WORDS Triphase System / Solid-Liquid-Solid / Phase Transfer Catalyst, / Poly(chloromethylstyrene) / Nucleophilic Reagent / Quaternary Salt /
\end{abstract}

Recently, phase transfer catalysis has been widely used in polymer chemistry such as polymeric phase transfer catalysts, polymer syntheses, and chemical modification of polymers. ${ }^{1.2}$ Some new phase transfer systems such as triphase systems, which can be used in reaction using gel polymer, have been developed. In the polymeric phase transfer catalyst, the triphase system has been studied in detail. ${ }^{3.4}$ These systems have some advantages such as facile separation and purification of products from the reaction mixture. In the reaction of a polymer, Fréchet et al. ${ }^{5}$ reported a liquid-liquid-solid triphase system consisting of an aqueous solution of nucleophilic reagent, an organic solvent, and chloromethylated polystyrene gel.

However, triphase systems of linear polymers have not been studied except for our previous communication. ${ }^{6}$ In that communication, it was found that the phase transfer reaction of linear poly(chloromethylstyrene) (PCMS) with solid nucleophilic reagent proceedes smoothly in solid-liquid-solid triphase system consisting of a solid nucleophilic reagent, an organic solvent, and solid PCMS

\footnotetext{
* To whom correspondence should be addressed.
}

under mild conditions using poor solvents such as $n$-hexane, cyclohexane, and diisopropyl ether.

This article reports the reaction mechanism in the solid-liquid-solid triphase transfer reaction of PCMS with nucleophilic reagents in the poor solvents, and discusses in detail suitable quaternary salts used as a phase transfer catalyst (PTC) and effect of stirring rate.

PCMS (the reduced viscosity in $N, N$ dimethylformamide (DMF) was $0.14 \mathrm{dlg}^{-1}$, measured at a concentration of $0.5 \mathrm{~g} \mathrm{dl}^{-1}$ at $30^{\circ} \mathrm{C}$ ) was prepared in $67 \%$ yield by radical polymerization of chloromethylated styrene (mixture of $40 \%$ of meta and $60 \%$ para). The typical procedure for the solid-liquid-solid triphase reaction of PCMS is described below. $0.610 \mathrm{~g}(4 \mathrm{mmol})$ of PCMS, $0.392 \mathrm{~g}(4 \mathrm{mmol})$ of potassium acetate, and $0.129 \mathrm{~g}(0.4 \mathrm{mmol})$ of tetrabutylammonium bromide (TBAB) were dispersed in $10 \mathrm{ml}$ of $n$-hexane. The mixture was stirred at $c a .300 \mathrm{rpm}$ by magnetic stirrer at $30^{\circ} \mathrm{C}$ for $48 \mathrm{~h}$, and then poured into $300 \mathrm{ml}$ of methanol. The obtained polymer was purified by reprecipitating twice from tetrahydrofuran (THF) into water and from THF into 
methanol, and was finally dried in vacuo at $50^{\circ} \mathrm{C}$. The yield of the resulting polymer was $0.549 \mathrm{~g}$ (the reduced viscosity was $0.15 \mathrm{dl} \mathrm{g}^{-1}$, measured at a concentration of $0.5 \mathrm{~g} \mathrm{dl}^{-1}$ in DMF at $30^{\circ} \mathrm{C}$ ). The degree of substitution was $19.8 \mathrm{~mol} \%$, calculated from elemental analysis of chlorine. The IR spectrum (film) showed absorptions at $1740(\mathrm{C}=\mathrm{O})$ and $1240 \mathrm{~cm}^{-1}$ $(\mathrm{C}-\mathrm{O}-\mathrm{C})$. The ${ }^{1} \mathrm{H}$ NMR spectrum $\left(\mathrm{CDCl}_{3}\right)$ showed $\delta=2.0 \quad\left(\mathrm{CO}-\mathrm{CH}_{3}\right)$ and $4.3 \mathrm{ppm}$ $\left(\mathrm{CH}_{2}-\mathrm{O}\right)$. These IR and ${ }^{1} \mathrm{H}$ NMR spectra of the polymer agree with those of the corresponding polymer prepared in solid-liquid two phase system. ${ }^{7}$

The solid-liquid-solid triphase reaction of PCMS with some nucleophilic reagents was carried out in the poor solvents using TBAB as a PTC at $30^{\circ} \mathrm{C}$ for $48 \mathrm{~h}$. As summarized in Table I, the reaction of PCMS with reagents took no place without PTC in $n$-hexane; how- ever, the addition of PTC caused the reaction to proceed smoothly. The polymers with relatively high degree of substitutions were obtained from the reaction of PCMS with some reagents such as potassium azide, potassium ethyl xanthate, and potassium thiophenolate in the triphase system. This suggests that the reaction occurs inside the polymer phase as well as on the surface of PCMS. In addition, the degree of substitution tended to decrease with increasing polarity of the solvent in the order: $n$-hexane $>$ cyclohexane $>$ diisopropyl ether. This may be attributed to the decreasing amount of PTC with a nucleophilic anion distributed from the organic phase to the polymer phase in that order. Therefore, PTC works between the non-polar organic phase and the relatively polar solid polymer phase as shown in the following scheme.

Solid polymer phase

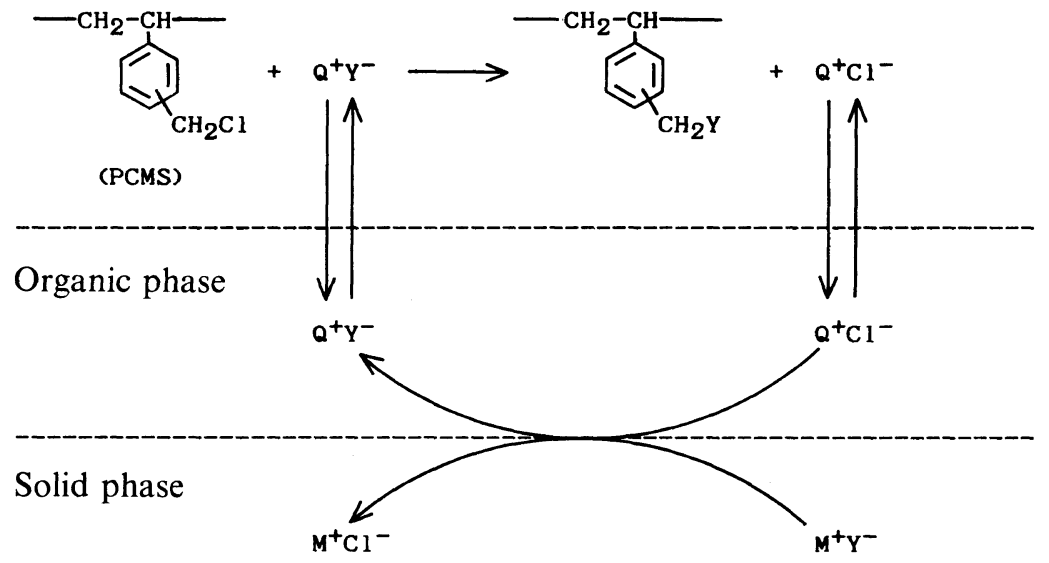

$\mathrm{M}^{+}$metal ion; $\mathrm{Q}^{+}$quaternary ion; $\mathrm{Y}^{-}$nucleophilic ion.

Scheme 1. PTC works between the non-polar organic phase.and the relatively polar solid polymer phase.

Stirring is an important factor in phase transfer reactions. The rate of reaction is independent of stirring over $200 \mathrm{rpm}$ in two phase system $^{8-10}$ and $800 \mathrm{rpm}^{11}$ or $400-500 \mathrm{rpm}^{12}$ in triphase system using polymeric phase transfer catalyst. However, this solid-liquidsolid triphase reaction was greatly affected by the stirring rate and the degree of substitution decreased with increase of stirring above 300 $\mathrm{rpm}$ as shown in Figure 1. The polymer was observed to leap out of the reaction system by stirring and to become attached to the surface of reaction flask when the stirring was too fast. Therefore, the other experiment was conduct- 
Table I. Substitution reaction of PCMS with nucleophilic reagents in a solid-liquid-solid triphase system

\begin{tabular}{|c|c|c|c|c|}
\hline \multirow[t]{2}{*}{ No. } & \multirow{2}{*}{$\begin{array}{l}\text { Nucleophilic } \\
\text { reagent }\end{array}$} & \multirow[t]{2}{*}{ Solvent } & \multirow[t]{2}{*}{ PTC } & $\begin{array}{l}\text { Degree of } \\
\text { substitution }\end{array}$ \\
\hline & & & & $\mathrm{mol}^{\circ} \%$ \\
\hline 1 & $\mathrm{CH}_{3} \mathrm{COOK}$ & $n$-Hexane & None & 0 \\
\hline 2 & $\mathrm{CH}_{3} \mathrm{COOK}$ & $n$-Hexane & TBAB & 19.8 \\
\hline 3 & $\mathrm{CH}_{3} \mathrm{COOK}$ & Cyclohexane & TBAB & 12.5 \\
\hline 4 & $\mathrm{CH}_{3} \mathrm{COOK}$ & DIPE $^{a}$ & TBAB & 42.4 \\
\hline 5 & $\mathrm{~N}_{3} \mathrm{~K}$ & $n$-Hexane & None & 0 \\
\hline 6 & $\mathrm{~N}_{3} \mathrm{~K}$ & $n$-Hexane & TBAB & 70.6 \\
\hline 7 & $\mathrm{~N}_{3} \mathrm{~K}$ & Cyclohexane & TBAB & 68.1 \\
\hline 8 & $\mathrm{~N}_{3} \mathrm{~K}$ & DIPE $^{a}$ & TBAB & 22.9 \\
\hline 9 & Pht. K & $n$-Hexane & None & 0 \\
\hline 10 & Pht. K ${ }^{b}$ & $n$-Hexane & TBAB & 13.9 \\
\hline 11 & NCSK & $n$-Hexane & None & 0 \\
\hline 12 & NCSK & $n$-Hexane & TBAB & 43.3 \\
\hline 13 & NCSK & Cyclohexane & TBAB & 35.7 \\
\hline 14 & NCSK & DIPE $^{a}$ & TBAB & 22.9 \\
\hline 15 & KSCSOEt & $n$-Hexane & None & 0 \\
\hline 16 & KSCSOEt & $n$-Hexane & TBAB & 56.1 \\
\hline 17 & KSCSOEt & Cyclohexane & TBAB & 68.1 \\
\hline 18 & KSCSOEt & DIPE $^{a}$ & TBAB & 47.1 \\
\hline 19 & $\mathrm{Ph}-\mathrm{COSK}$ & $n$-Hexane & None & 0 \\
\hline 20 & $\mathrm{Ph}-\mathrm{COSK}$ & $n$-Hexane & TBAB & 32.2 \\
\hline 21 & $\mathrm{Ph}-\mathrm{SK}$ & $n$-Hexane & None & 9.6 \\
\hline 22 & Ph-SK & $n$-Hexame & TBAB & 79.8 \\
\hline
\end{tabular}

The reaction was carried out with $4 \mathrm{mmol}$ of PCMS, $4 \mathrm{mmol}$ of the nucleophilic reagent, and $0.4 \mathrm{mmol}$ of PTC at $30 \mathrm{C}$ for $48 \mathrm{~h}$.

a Diisopropyl ether.

b Potassium phthalimide.

ed by stirring at $c a .300 \mathrm{rpm}$.

The effects of counter ion and length of the alkyl chains in tetraalkylammonium salts were investigated in the reaction of PCMS with potassium azide in $n$-hexane. As shown in Figure 2, the catalytic activity was markedly affected by the hydrophilicity of counter ions, which decreased in the following order: $\mathrm{HSO}_{4}{ }^{-}>\mathrm{Cl}^{-}>\mathrm{Br}^{-}>\mathrm{I}^{-}>\mathrm{ClO}_{4}{ }^{-13}$ Although the quaternary ammonium salts containing hydrophilic $\mathrm{HSO}_{4}$ and lipophilic $\mathrm{ClO}_{4}{ }^{-}$ anions showed low activity, TBAB had the highest activity in tetrabutylammonium salts. This agrees well with the result for the two phase transfer reaction of PCMS. ${ }^{9}$

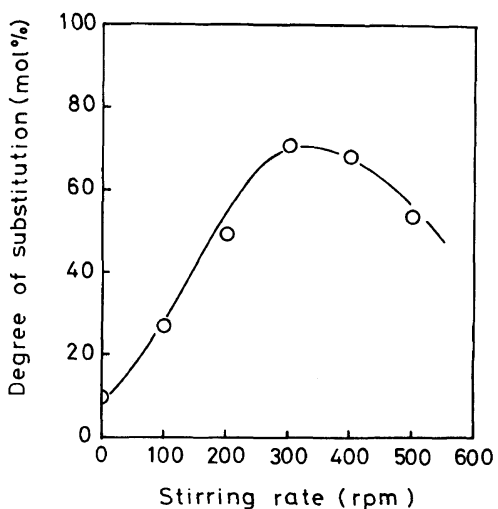

Figure 1. Effect of stirring rate by a magnetic stirrer on the solid-liquid-solid triphase reaction of PCMS with potassium azide in $n$-hexane using TBAB as a PTC at $30^{\circ} \mathrm{C}$ for $48 \mathrm{~h}$.

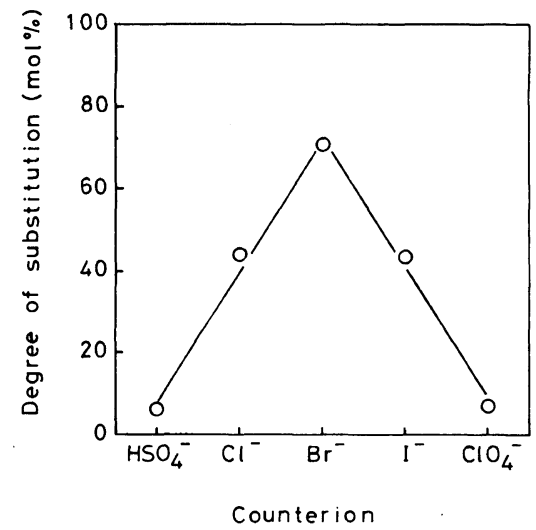

Figure 2. Relation between the degree of substitution and counter ion of tetrabutylammonium salt by the solid-liquid-solid triphase reaction of PCMS with potassium azide in $n$-hexane using TBAB as a PTC at $30^{\circ} \mathrm{C}$ for $48 \mathrm{~h}$.

Furthermore, TBAB showed the highest catalytic activity of tetraalkylammonium bromides in the triphase system, whereas tetrapentylammonium bromide (TPeAB) was the best PTC in the two phase transfer reaction of PCMS, ${ }^{9}$ as shown in Figure 3. It is well-known that a tetraalkylammonium salt with lipophilic long alkylchains shows high catalytic activity as a PTC. ${ }^{14}$ However, the catalytic activity of quaternary ammonium salt interfered with steric hindrance between the quaternary am- 


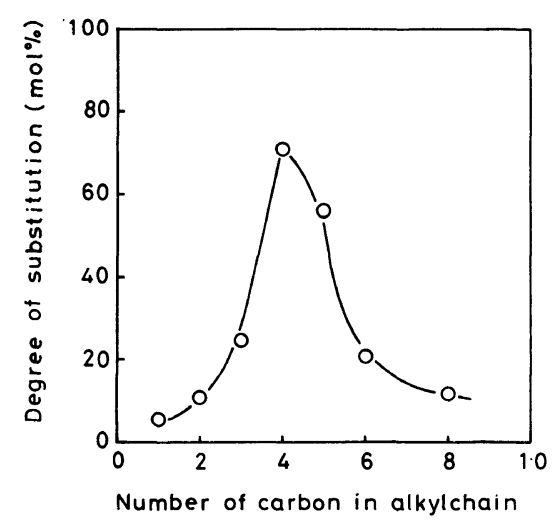

Figure 3. Relation between the degree of substitution and chain length in tetraalkylammonium bromides by the solid-liquid-solid triphase reaction of PCMS with potassium azide in $n$-hexane using TBAB as a PTC at $30^{\circ} \mathrm{C}$ for $48 \mathrm{~h}$.

monium salt and polymer chain. Therefore, a tetraalkylammonium bromide which has good balance between lipophilicity and steric hindrance shows maximum catalytic activity, which depends on the structure of the polymer containing chlorine. ${ }^{9,10,15}$ In this case, it seems that the mobility of the bulky quaternary ammonium salts was strongly restricted by steric hindrance between the quaternary salts and the polymer chain in the solid polymer phase. Accordingly, a bulky quaternary ammonium salt such as TPeAB showed relatively lower catalytic activity in the solid-liquidsolid triphase system, compared with the solid-liquid two phase system. ${ }^{9}$ This suggests that the activity of quaternary ammonium salts is also influenced by the surroundings of the polymer.

\section{REFERENCES}

1. T. Nishikubo, Kobunshi, 35, 132 (1986).

2. L. J. Matias and C. E. Carraher Jr. Ed., "Crown Ether and Phase Transfer Catalysis in Polymer Science," Plenum Press, New York, N.Y., 1984.

3. S. L. Regen, Angew. Chem., Int. Ed. Engl., 18, 421 (1979).

4. W. T. Ford and M. Tomoi, Adv. Polym. Sci., 55, 49 (1984).

5. J. M. J. Fréchet, M. C. de Smet, and M. J. Farrall, J. Org. Chem., 44, 1774 (1979).

6. T. Nishikubo, T. Iizawa, S. Akatsuka, and M. Okawara, Polym. J., 15, 911 (1983).

7. T. Iizawa, T. Nishikubo, Y. Masuda, and $\mathbf{M}$. Okawara, Macromolecules, 17, 992 (1984).

8. C. M. Starks and R. M. Owens, J. Am. Chem. Soc., 95, 3613 (1973).

9. T. Nishikubo, T. Iizawa, K. Kobayashi, Y. Masuda, and M. Okawara, Macromolecules, 16, 722 (1983).

10. T. Iizawa, T. Nishikubo, M. Ichikawa, Y. Sugawara, and M. Okawara, J. Polym. Sci., Polym. Chem. Ed., 23, 1783 (1985)

11. H. Montanari, F. Montanari, S. Quici, and P. Tundo, J. Am. Chem. Soc., 101, 3920 (1979).

12. M. Tomoi and W. T. Ford, J. Am. Chem. Soc., 103, 3821 (1981).

13. C. M. Starks and C. Liotta, "Phase Transfer Catalysis," Academic Press, New York, N.Y., 1978.

14. A. W. Heririott and D. Picker, J. Am. Chem. Soc., 97, 2345 (1975).

15. T. Nishikubo, T. Iizawa, N. Numazaki, and $\mathbf{M}$. Okawara, Makromol. Chem., Rapid Commun., 4, 187 (1983). 